\title{
Polish Geological Cartography Platform: one access point to all geological maps
}

\author{
Katarzyna Jóźwik $^{\text {a, }}$, , Anita Starzycka ${ }^{\text {a }}$, Piotr Gałkowski ${ }^{\text {, }}$, Józef Mikołajków ${ }^{\text {a }}$ \\ ${ }^{a}$ Polish Geological Institute - National Research Institute, katarzyna.jozwik@pgi.gov.pl, anita.starzycka@pgi.gov.pl, \\ piotr.galkowski@pgi.gov.pl,jozef.mikolajkow@pgi.gov.pl \\ * Corresponding author
}

Keywords: Thematic maps, WPKG, spatial data services, web application

\begin{abstract}
:
Everybody who plans an infrastucture investment, prepares a zoning plan or just wants to install a heat pump, knows how important it is to have an access to geological information. Geological cartography resources are used by entrepreneurs, local governments, scientists, students and other citizens who need to obtain data on geological structure or hydrogeological as well as environmental conditions of the region. Contextual analysis of thematically diverse geological maps along with administrative, topographic or other reference data are the basis of any geological work - both applied or scientific. According to the statistical analysis, a "geological map" phrase is one of the most searched on the website of the Polish Geological Institute - National Research Institute (PGI-NRI).
\end{abstract}

Following the needs of the economy, science and society, the PGI-NRI, as one of the first geological surveys in Europe, provided online access to serial geological maps. More than 5000 map sheets have been made available, in the form of raster files, since 2016. As one of the tasks of the Polish geological survey, a Polish Geological Cartography Platform (Polish name: Wspólna Platforma Kartografii Geologicznej, Polish abbreviation: WPKG) is currently being developed at the PGI-NRI. A complex database of all known cartographic products together with a specialized online GIS tools will make the use of maps easier than ever before. Strategic resources of the Polish geological cartography the PGI-NRI and other geologists have built over the last decades will be secured and made widely available with the use of state-of-the-art digital tools. The resources will be available through web application which also provides user-friendly search, analysis and download tools".

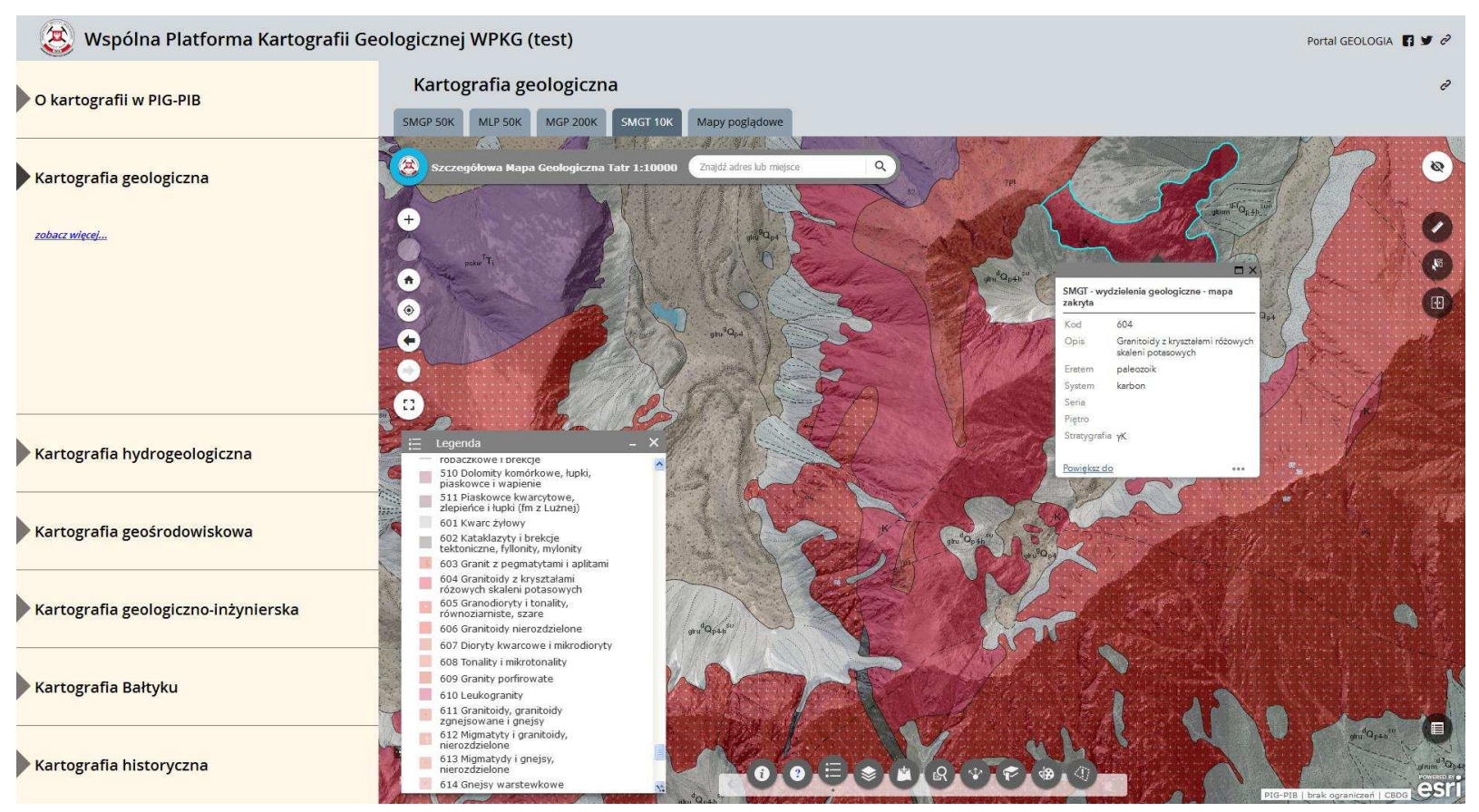

Figure 1. Screenshot of the test version of the Polish Geological Cartography Platform (WPKG) web application

In the frame of the Polish Geological Cartography Platform, a total of about 20000 files and spatial data services will be collected, configured or developed, and made available by the end of 2023. The platform will cover both the latest cartographic products and archival geological maps compiled by the PGI-NRI and other scientific institutions, specifically: the Detailed Geological Map of Poland to the scale of 1:50 000, geological maps of Poland to the scales of 1:200 000, 1:500 000, 1:1 000 000, Polish part of the International Quaternary Map of Europe to the scale of 
1:2 500000 (IQUAME 2500), Hydrogeological Map of Poland to the scale of 1:50 000, Geo-environmental Map of Poland, maps of flood risk areas, geological and geotechnical maps of major urban agglomerations as well as many other regional and thematic maps.

Maps will be available as raster files (along with cross-sections, sketches, text explanations etc.) and/or view and download services (WMS/WFS, REST API). Users will be able to add to the view and include their own data in the analysis and save the resulting map. By the appropriate arrangement of the database and the use of common GIS geostatistical functions, the Polish Geological Cartography Platform web application will make it possible to perform various queries and spatial analyses, concerning i.a. lithology, age and genesis of the deposits presented in the maps. Among the others, it will enable to determine the location of objects with selected parameters/attributes e.g. to find rocks of specific lithology in the area of particular administrative unit. Data search, view and download mechanisms will be improved by the introduction of additional search options (e.g. by administrative units, map sheet division, selected keywords) while their performance will be increased by the employment of efficient GIS architecture, modern GIS servers and technologically optimal system for data storage and retrieval. The GIS solutions provided by ESRI will be the key components of the Polish Geological Cartography Platform.

For the convenience of everybody who uses the PGI-NRI cartographic resources online, a citation standard for the PGINRI maps and cartographic products will be developed. An appropriate description ("cite as") for each map/product will be ready to download, in the web application, together with the maps themselves. It will be also possible to generate and download a consolidated ready-to-use list of the downloaded maps which will significantly facilitate the compilation of a list of source studies e.g. for scientific papers.

All works are financed by the Polish National Fund for Environmental Protection and Water Management. 